\title{
Kajian Karakteristrik Alat Ukur dan Sensor Standar pada Proses Kalibrasi Data Sensor Cahaya
}

\author{
Ellys Kumala P dan Endarko* \\ Jurusan Fisika-FMIPA, Institut Teknologi Sepuluh Nopember \\ Kampus ITS Sukolilo, Surabaya 61111
}

\begin{abstract}
Intisari
Telah dilakukan penelitian mengenai kajian variasi alat standar dan karakteristik sensor terhadap kalibrasi sensor cahaya. Pada artikel ini, akuisisi data sensor cahaya dilakukan pada 2 sensor cahaya yaitu Light Dependent Resistor (LDR) dan fotodioda dengan menggunakan kalibrator net log dan lux meter. Sistem kalibrasi dirancang untuk kondisi yang konstan pada setiap pengukurannya. Pengukuran dilakukan untuk variasi jarak sensor terhadap sumber cahaya dan ukuran variasi diameter lubang penghalang di atas sensor untuk menghasilkan perubahan iluminansi cahaya yang diterima sensor. Hasil penelitian menunjukkan bahwa LDR memiliki respon yang lebih baik dibandingkan dengan fotodioda, nilai iluminansi cahaya berkurang seiring dengan semakin jauhnya jarak sensor dengan sumber cahaya dan semakin kecilnya diameter lubang penghalang masuknya cahaya ke sensor.

KATA KUNCI: cahaya, LDR, iluminasi, fotodioda
\end{abstract}

\section{PENDAHULUAN}

Cahaya merupakan gelombang elektromagnetik yang mempunyai jangkauan panjang gelombang antara (380 - 750) $\mathrm{nm}$ dan dapat dilihat oleh mata manusia. Besaran-besaran fotometri pada cahaya antara lain fluks cahaya, intensitas cahaya, iluminansi, luminansi dan faktor refleksi [1]. Intensitas cahaya merupakan salah satu besaran pokok fisika untuk mengukur daya yang dipancarkan sumber cahaya pada arah tertentu per satuan sudut [2]. Intensitas sumber cahaya bernilai konstan, sementara kuat penerangan cahaya (iluminasi) merupakan fluks cahaya yang terpancar oleh sumber cahaya terhadap suatu bidang [3].

Terdapat berbagai macam sensor untuk mengukur iluminansi cahaya antara lain Light Dependent Resistor (LDR), fotodioda, tabung fotomultiplier, dan fototransistor [4]. Dalam pendeteksian iluminansi cahaya, perlu dilakukan proses kalibrasi sensor dengan alat standar agar didapatkan proses pembacaan nilai iluminansi yang benar. Beberapa faktor pada proses kalibrasi antara lain kondisi alat standar, faktor lingkungan, dan karakteristik sensor yang digunakan, sering kali terabaikan sehingga dapat menyebabkan kesalahan dalam pengukuran. Karakteristik alat standar perlu dilakukan evaluasi untuk menjamin tingkat keakurasian dalam memberikan hasil pengukuran. Kondisi lingkungan pada sistem pengukuran juga perlu diperhatikan untuk mendapatkan kondisi yang ideal pada proses kalibrasi [5]. Sementara itu, karakteristik sensor perlu diperhatikan agar dapat dipilih sensor mana yang paling baik dan cocok untuk pendeteksian sensor cahaya. Untuk itu perlu dilakukan proses kalibrasi dengan menggunakan variasi alat standar untuk menjamin kesamaan hasil pemba-

*E-MAIL: endarko@physics.its.ac.id caan yang dihasilkan oleh sensor cahaya [6].

Dalam penelitian ini digunakan 2 sensor cahaya yaitu LDR dan fotodioda. LDR merupakan salah satu komponen elektronika yang nilai hambatannya akan turun seiring dengan pertambahan intensitas cahaya yang diterima oleh sensor [7]. Sedangkan fotodioda merupakan sebuah dioda dengan sambungan p-n yang akan dipanjar maju apabila cahaya mengenai sensor [7]. Proses kalibrasi kedua sensor dilakukan dengan menggunakan alat standar Net Log Light Sensor U11364 (3B Scientific Physics) dan lux meter (LX-1108 buatan Lutron).

Dalam penelitian ini juga dilakukan pengamatan terhadap pengaruh jarak terhadap sensor dengan sumber cahaya dan diameter lubang penghalang masuknya cahaya terhadap besarnya iluminansi cahaya yang diterima sensor.

\section{METODOLOGI PENELITIAN}

Pada penelitian ini digunakan LDR dan fotodioda sebagai sensor cahaya dan 2 alat standar net $\log$ dan lux meter untuk proses kalibrasinya. Gambar 1 menunjukkan rangkaian masing-masing sensor yang digunakan, yang dirangkai dengan resistor $33 \mathrm{k} \Omega$ membentuk rangkaian pembagi tegangan.

Sistem kalibrasi (Gambar 2), dirancang dengan membuat sebuah ruang kotak tertutup berukuran $(1,5 \times 0,5 \times 0,5)$ $\mathrm{m}^{3}$ yang digunakan sebagai ruang gelap tempat pengambilan data. Ruang gelap ini dimaksudkan agar tidak ada cahaya luar yang mempengaruhi pengukuran pada saat proses kalibrasi sensor dengan alat standar, serta diharapkan agar kondisi lingkungan untuk setiap pengukuran selalu sama. Sensor dan alat standar diletakkan pada sebuah kotak berukuran $(27 \times 19$ $\times 15) \mathrm{cm}^{3}$ dengan dua buah tongkat penyangga untuk variasi jarak terhadap sensor dan sumber cahaya. Sumber cahaya pada penelitian ini digunakan bola lampu 12 volt dengan daya 35 watt.

Alat ukur standar yang digunakan adalah net $\log$ dan lux 


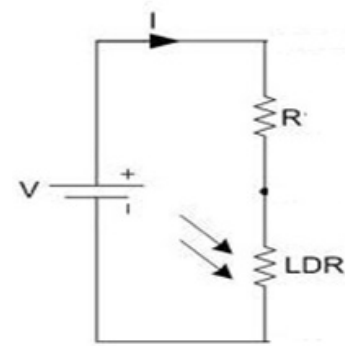

(a)rangkaian LDR

Gambar 1: Gambaran konversi informasi
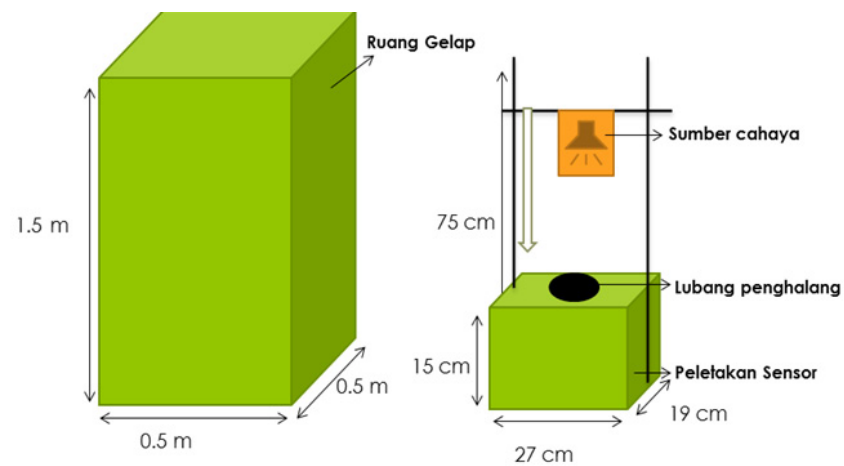

Gambar 2: Sistem kalibrasi

meter. Sensor cahaya pada net log ini berbentuk kotak menggabungkan dioda dengan filter optik untuk pengukuran intensitas cahaya (iluminansi), terutama di daerah tampak. Pada sensor ini memiliki tabung $8 \mathrm{~mm}$ untuk mencegah masuknya cahaya yang tidak diinginkan dari sisi-sisi sensor. Sedangkan sensor cahaya pada lux meter menggunakan fotodioda dengan filter koreksi warna. Alat ukur ini memiliki sensor yang cukup besar sehingga memungkinkan semakin banyak cahaya yang masuk.

Pengukuran yang pertama dilakukan adalah pengukuran terhadap alat standar. Alat standar diletakkan tepat di bawah sumber cahaya dengan variasi jarak 5, 10 dan $15 \mathrm{~cm}$. Pengukuran dilakukan dengan memvariasi tingkat kecerahan cahaya dengan kenaikan tegangan lampu 0,5 volt untuk tegangan antara 0 - 12 volt. Untuk proses pengukuran pada LDR dan fotodioda, pengambilan data dilakukan sama seperti pada proses pengukuran menggunakan alat standar.

Selanjutnya dilakukan pengukuran dengan variasi jarak sensor dengan sumber cahaya dan variasi diameter lubang masuk cahaya pada sensor untuk mengetahui pengaruh keduanya terhadap iluminansi cahaya yang diterima sensor. Variasi jarak sensor dengan sumber cahaya dilakukan dengan pertambahan $3 \mathrm{~cm}$ hingga jarak maksimum $24 \mathrm{~cm}$. Sedangkan lubang masuknya cahaya divariasi dengan jari-jari 0,5, 1, 2 dan $3 \mathrm{~cm}$.

\section{HASIL}

Gambar 3 menunjukkan pembacaan iluminansi cahaya (lux) untuk mengetahui respon sensor LDR dan fotodioda pada jarak 5, 10 dan $15 \mathrm{~cm}$ terhadap sumber cahaya dengan menggunakan alat ukur standar net log dan lux meter. Gambar 3a, b dan c merupakan grafik tegangan - lux pada pengukuran sensor LDR, dan Gambar 3d, e dan f merupakan grafik tegangan-lux pada pengukuran sensor fotodioda.

Hasil pada Gambar 3 menunjukkan bahwa alat ukur net log mampu melakukan pembacaan pada tingkat iluminansi cahaya yang rendah, dibandingkan dengan lux meter. Pada saat lampu diberi tegangan $(0-1,5)$ volt, net log mampu memberikan hasil pengukuran sebesar $(0,6-0,8)$ lux, sementara pada lux meter belum menunjukkan nilai iluminansi cahaya. Namun pada tingkat iluminansi cahaya tinggi lux meter mampu melakukan pembacaan hingga 2013 lux, sementara pada net log di atas 425 lux pembacaan lux pada net log menjadi tidak konstan. Perbandingan respon sensor LDR dan fotodioda yang diukur dengan menggunakan net log maupun lux meter ditunjukan pada Gambar 4.

Gambar 4 memperlihatkan kenaikan tegangan respons sensor LDR dan fotodioda terhadap kenaikan iluminansi cahaya. Respon LDR membentuk tren eksponensial sementara pada fotodioda membentuk tren kenaikan yang berubah cukup tajam saat saturasi. LDR mulai mengalami saturasi pada iluminansi (48 - 95) lux tergantung variasi jarak yang dilakukan. Sedangkan fotodioda mulai mengalami saturasi pada $(3,8$ 26,6) lux. Pada Gambar 4 terlihat bahwa LDR memiliki data kenaikan respon yang lebih lambat dibandingkan dengan fotodioda.

Kemudian pengukuran dilakukan dengan tingkat penerangan lampu dibuat konstan pada tegangan 4 volt, namun jarak sensor terhadap sumber cahaya divariasi dengan kenaikan 3 $\mathrm{cm}$. Hasil pengukuran pada masing-masing sensor dapat ditunjukkan pada Gambar 5.

Gambar 5 menunjukkan penurunan tegangan keluaran sensor ketika jarak semakin jauh terhadap sumber cahaya. Penurunan LDR mempunyai kecenderungan lebih linier dibandingkan dengan fotodioda. Pada fotodioda mengalami penurunan bertahap pada jarak $(3-15) \mathrm{cm}$ namun menurun secara tajam pada jarak $(15-21) \mathrm{cm}$.

Pengukuran yang terakhir dilakukan adalah variasi jari-jari lubang masuknya sumber cahaya. Lubang berada $15 \mathrm{~cm}$ tepat di atas sensor. Jari-jari lubang divariasi dengan ukuran 0,5, 1 , 2 , dan $3 \mathrm{~cm}$. Sumber cahaya dibuat konstan dengan tegangan 10 volt. Hasil pengukuran pada masing-masing sensor dapat ditunjukkan pada Gambar 6.

Berdasarkan hasil Gambar 6 terlihat bahwa untuk variasi jari-jari lubang 3, 2 dan $1 \mathrm{~cm}$ tidak menunjukkan perubahan respon sensor yang cukup besar. Namun pada jari-jari lubang $0,5 \mathrm{~cm}$ memperlihatkan penurunan respon yang cukup besar.

\section{PEMBAHASAN}

Perbandingan pembacaan iluminasi cahaya oleh net log dan lux meter yang ditunjukan Gambar 3, dapat dianalisis sebagai 


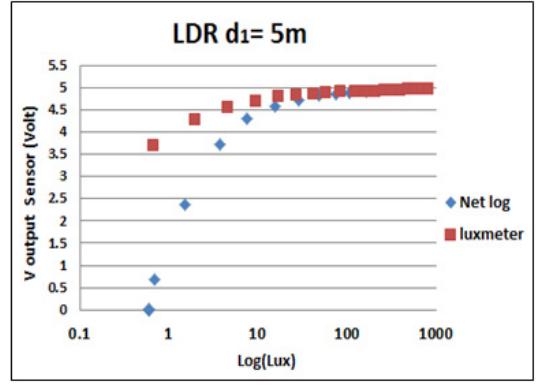

(a)

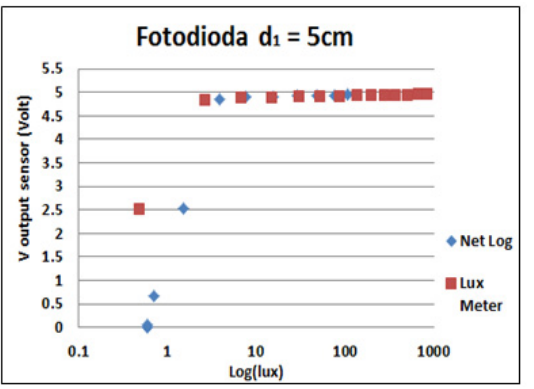

(d)

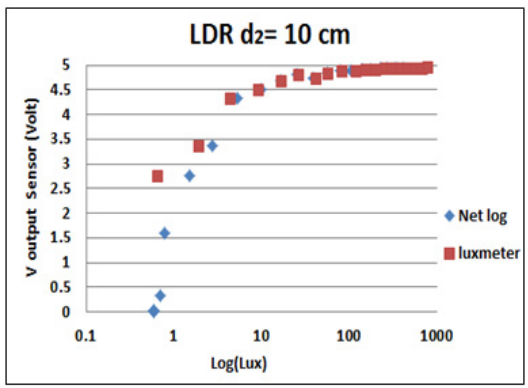

(b)

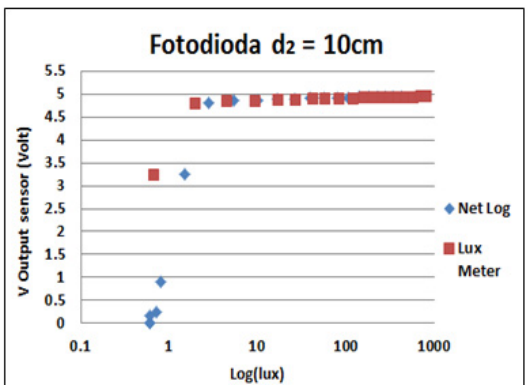

(e)

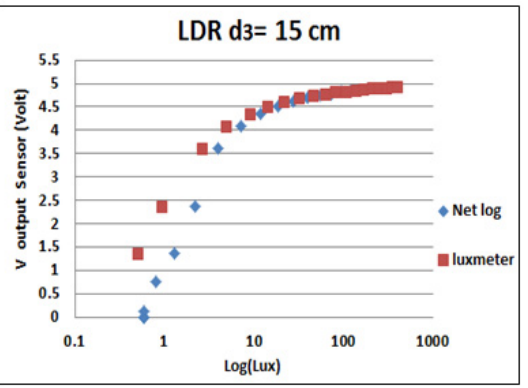

(c)

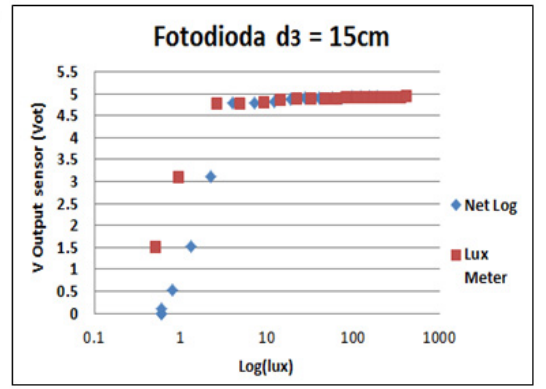

(f)

Gambar 3: Grafik perbandingan pembacaan net log dan lux meter pada masing-masing sensor

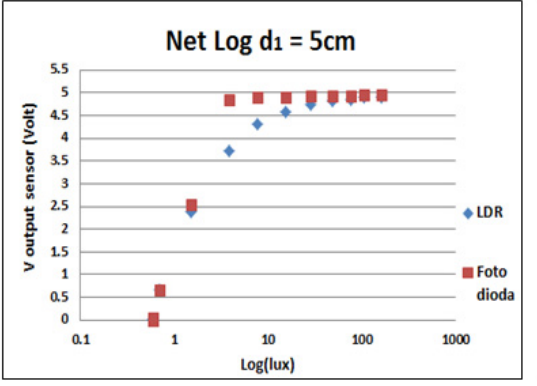

(a)

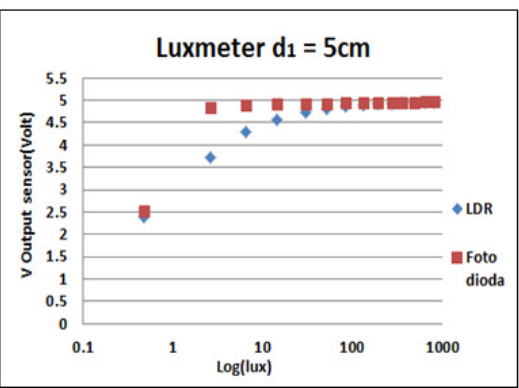

(d)

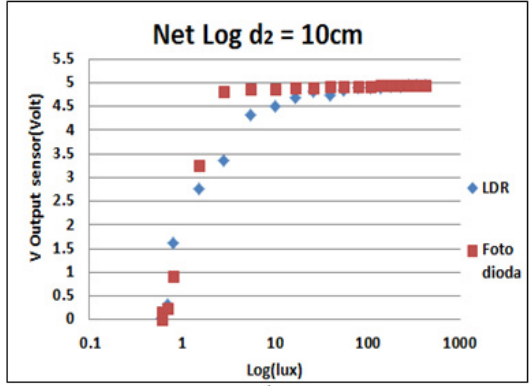

(b)

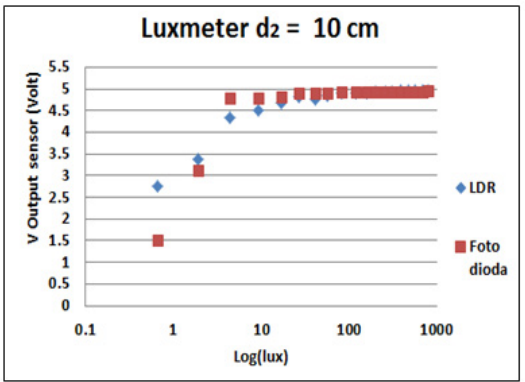

(e)

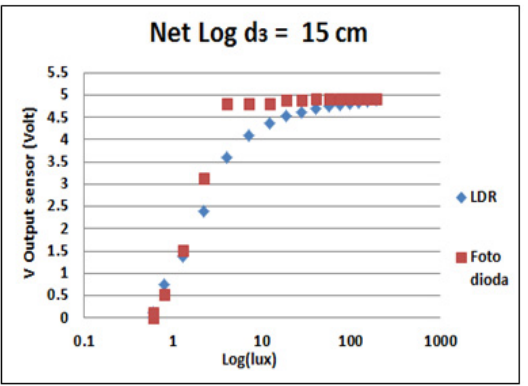

(c)

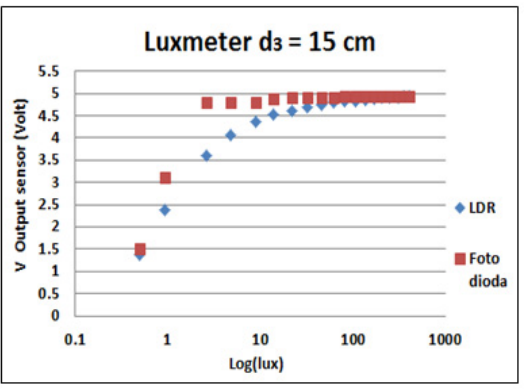

(f)

Gambar 4: Grafik perbandingan respon LDR dan fotodiodapada pembacaan net log dan lux meter

berikut; pada proses kalibrasi terlihat bahwa masing-masing alat standar memiliki tingkat sensitivitas yang berbeda-beda. net log memiliki tingkat sensitivitas yang tinggi pada rentang iluminasi yang rendah sementara lux meter memiliki tingkat sensitivitas yang tinggi pada rentang iluminasi yang tinggi. Pada saat dilakukan pengukuran, pembacaan pada net log cen- derung tidak konstan saat tingkat penerangan tinggi, sedangkan pada pada lux meter, pada tingkat penerangan rendah tidak menunjukan pembacaan nilai iluminasi.

LDR dan fotodioda memiliki karakter yang berbeda dalam mendeteksi iluminasi cahaya. Pada Gambar 4 terlihat bahwa LDR menunjukkan tren respon yang cenderung ekponensial, 


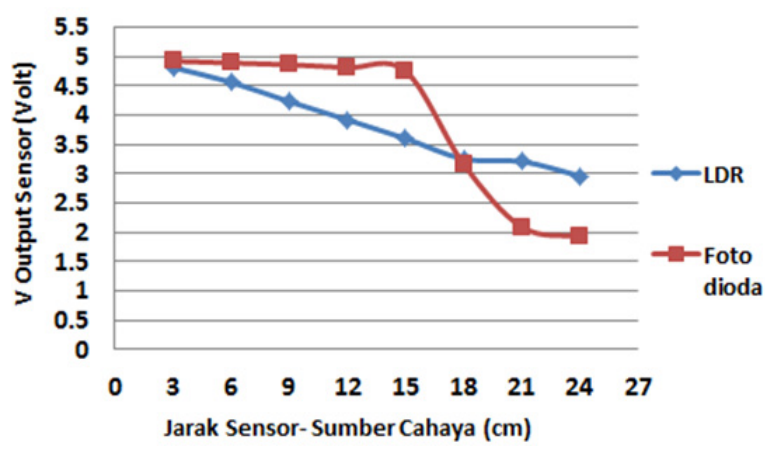

Gambar 5: Grafik hubungan variasi jarak sensor-sumber cahaya dengan tegangan output sensor

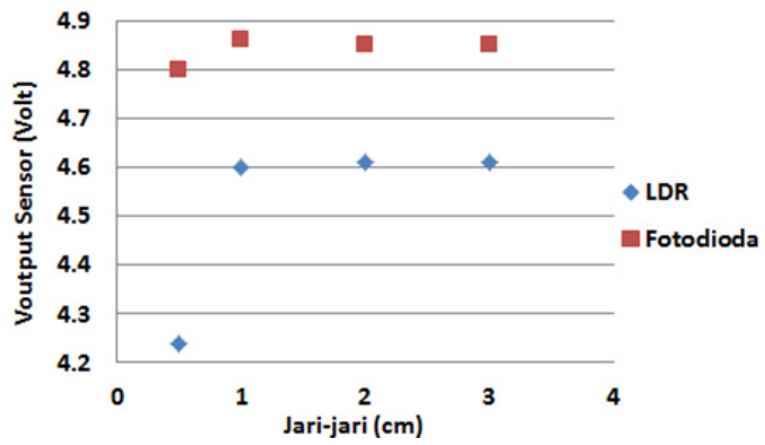

Gambar 6: Grafik hubungan variasi ukuran lubang masuknya cahaya dengan tegangan output sensor

sedangkan pada fotodioda mengalami kenaikan yang linier pada awal kenaikan kemudian berubah secara tajam pada saat mulai saturasi. Selain itu fotodioda juga jauh lebih cepat saturasi dibandingkan dengan LDR, sehingga fotodioda memiliki data kenaikan yang lebih sedikit pada saat kenaikan linier dibandingkan LDR.

Jarak sensor-sumber cahaya yang semakin tinggi menyebabkan tegangan output sensor semakin kecil. Hal ini ditunjukkan pada Gambar 5. LDR dan fotodioda memiliki tren respon yang berbeda pada pengukuran dengan variasi jarak sensor-sumber cahaya ini. LDR turun dengan tren yang cukup linier dibandingkan fotodioda. Fotodioda pada jarak yang lebih dekat dengan sumber cahaya cenderung memiliki perubahan yang kecil namun saat jarak $15 \mathrm{~cm}$ tegangan turun tajam. Hal ini disebabkan pada jarak yang dekat $(<15$ $\mathrm{cm}$ ) dengan sumber cahaya, fotodioda mengalami saturasi. Sedangkan variasi ukuran lubang yang telah dilakukan didapatkan nilai yang cukup mirip pada lubang dengan jari-jari 1, 2, dan $3 \mathrm{~cm}$ (ditunjukkan pada Gambar 6). Namun pada jari-jari 0,5 cm perubahan tegangan keluaran cukup terlihat. Semakin kecil lubang yang dibuat semakin kecil iluminasi yang diterima oleh sensor.

\section{SIMPULAN}

Dari penelitian ini dapat kesimpulan bahwa kedua alat standar yang digunakan memiliki tingkat sensitivitas yang berbeda. Net log memiliki sensitivitas yang cukup tinggi untuk cahaya redup, namun untuk cahaya yang terang lux meter mampu bekerja lebih baik dibanding dengan net log. Kemudian dari dua sensor yang dibandingkan pada penelitian ini terlihat bahwa LDR memiliki respon yang lebih baik dalam pendeteksian iluminansi cahaya karena fotodioda cenderung lebih cepat saturasi dibanding dengan sensor LDR.

Variasi jarak sensor dengan sumber cahaya dan variasi lubang masuknya cahaya menunjukkan semakin besar jaraknya maka nilai tegangan keluaran yang dihasilkan semakin kecil. Semakin kecil jari-jari lubang yang dibuat maka semakin kecil iluminansi cahaya yang diterima oleh sensor.
[1] Muhaimin, Teknologi Pencahayaan (Refika Aditama, Bandung, 2001).

[2] D.B. Rahmat, Diktat Fisika Bangunan (ITS, Surabaya, 2004).

[3] W.H. Hanley, The IESNA Lighting Handbook (The Illuminating Engineering Society of North America, New York, 2000).

[4] J. Freden, Handbook of Sensor 2004 (Springer-Verlag, 2000).

[5] P.P.L. Regtien, Measurement Science for Engineers (Kogan Page
Science, London, 2004).

[6] D.C. Montgomery,Design and Analysis of experiment (John Willey and Son, New York, 2000).

[7] O. Bishop, Understand Electronic Control Systems (Elsevier Science, 1995). 